OPEN ACCESS

Edited by:

Dongri Song,

Institute of Mountain Hazards and Environment (CAS), China

Reviewed by: Xiangyu $\mathrm{Li}$,

University of Alberta, Canada Yu Wang,

University of Science and Technology Beijing, China

${ }^{*}$ Correspondence: Yingjie Xia

xiayingjie@dlut.edu.cn

Specialty section: This article was submitted to

Geohazards and Georisks,

a section of the journal

Frontiers in Earth Science

Received: 03 November 2021 Accepted: 24 November 2021

Published: 14 January 2022

Citation:

Bao C, Zhan L, Xia Y, Huang Y and Zhao Z (2022) Development Trend and Stability Analysis of Creep Landslide With Obvious Slip Zone Under RainfallTaking Xinchang Xiashan Basalt Slope

as an Example.

Front. Earth Sci. 9:808086 doi: 10.3389/feart.2021.808086

\section{Development Trend and Stability Analysis of Creep Landslide With Obvious Slip Zone Under Rainfall-Taking Xinchang Xiashan Basalt Slope as an Example}

\author{
Chunyan Bao ${ }^{1,2}$, Lingtao Zhan ${ }^{1,2}$, Yingjie Xia ${ }^{3 *}$, Yongliang Huang ${ }^{1}$ and Zhenxing Zhao ${ }^{4}$ \\ ${ }^{1}$ School of Civil Engineering, Shaoxing University, Shaoxing, China, ${ }^{2}$ Collaborative Innovation Center for Prevention and Control of \\ Mountain Geological Hazards of Zhejiang Province, Shaoxing, China, ${ }^{3}$ State Key Laboratory of Coastal and Offshore Engineering, \\ Dalian University of Technology, Dalian, China, ${ }^{4}$ China Railway Construction Bridge Engineering Bureau Group 3rd Engineering \\ Co., Shenyang, China
}

The creep slope is a dynamic development process, from stable deformation to instability failure. For the slope with sliding zone, it generally creeps along the sliding zone. If the sliding zone controlling the slope sliding does not have obvious displacement, and the slope has unexpected instability without warning, the harm and potential safety hazard are often much greater than the visible creep. Studying the development trend of this kind of landslide is of great significance to slope treatment and landslide early warning. Taking Xiashan village landslide in Huishan Town, Xinchang County, Zhejiang Province as an example, the landslide point was determined by numerical simulation in 2006. Generally, the landslide is a typical long-term slow deformation towards the free direction. Based on a new round of investigation and monitoring, this paper shows that there are signs of creeping on the surface of the landslide since 2003, and there is no creep on the deep sliding surface. The joint fissures in the landslide area are relatively developed, and rainfall infiltration will soften the soft rock and soil layer and greatly reduce its stability. This paper collects and arranges the rainfall data of the landslide area in recent 30 years, constructs the slope finite element model considering rainfall conditions through ANSYS finite element software, and carries out numerical simulation stability analysis. The results show that if cracks appear below or above the slope's sliding surface, or are artificially damaged, the sliding surface may develop into weak cracks. Then, the plastic zone of penetration is offset; In the case of heavy rain, the slope can unload itself under the action of rainfall. At this time, the slope was unstable and the landslide happened suddenly.

Keywords: xiashan village landslide, numerical simulation, rainfall, slope stability, creep

\section{INTRODUCTION}

With the development of large-scale construction projects in the fields of mining, water conservancy, transportation and construction, a large number of large-scale and complex geological conditions have been encountered, such as mine slopes, dam collapses and reservoir bank landslides, which have made a big step forward in the study of landslide stability. A variety of methods based on elastic- 
plastic theory and the application of improved limit equilibrium methods emerge as times require. In particular, people try to use the finite element method to study the stability of slope, which creates conditions for the quantitative evaluation of landslide stability and makes it gradually transit to the numerical method (Kaya and Midili, 2020; Shaller et al., 2020).

Over the years, many scholars have carried out a lot of research on landslide failure mechanism and stability (Marino et al., 2020; Wasowski and Pisano, 2020; Zhang, 2020; Zhang et al., 2020; Ramesh, 2021; Zheng et al., 2021), considering the slope in water (Salmasi et al., 2020). Study the Impact of Climate Change on Landslides (Lin et al., 2020; Shan et al., 2020; Zheng et al., 2021). Under the action of seepage, the failure mechanism and stability of slope are studied. Through the investigation of the landslide site, the formation mechanism of landslides was studied. Analysis of slope by field investigation and numerical simulation of body stability under heavy rainfall; through the combination of physical simulation and numerical simulation, the failure mechanism of landslides induced by heavy rainfall after coal seam mining is analyzed (Rauter et al., 2021; Zhou et al., 2021). The deformation and failure mechanism is as follows: goaf rock $\rightarrow$ slope deformation $\rightarrow$ rainfall-induced slope overall deformation evolution $\rightarrow$ sliding surface expansion $\rightarrow$ landslide occurrence (Li et al., 2021; Yang et al., 2021).

The activities of rainfall and groundwater level are the main factors that cause landslides. Foreign scholars (Naidu et al., 2018) have proposed analyzing and establishing a correlation between rainfall and the safety factor of landslides. According to the field test data of the Xiashan landslide, it is found that there are obvious differences in the seepage amount at different survey points. Using numerical software, we can simulate a slope landslide under different rainfall conditions.

Creep slope refers to the slope whose sliding deformation of rock and soil mass has obvious creep characteristics under the action of gravity, that is, its deformation has the characteristics of slow growth and evolution with time. This kind of slope is a dynamic development process, from stable deformation to instability failure. The stress and strain of rock and soil mass constantly develop and change with the change of time, and the change process often lasts for a long time (Yu et al., 2006; Guang et al., 2008; He et al., 2016; Marin and Velásquez et al., 2020).

Alpine landslides have strong destructive power when they occur, which can change the topography of the earth's surface (alpine and deep valley systems located on land and ocean). The valley's landscape is severely affected by the downhill movement of large landslides and the destruction of forest vegetation, threatening wildlife living on the surface of the earth and rivers, lakes and oceans. Secondly, whether the building is located on or near a landslide, landslide will affect it. Residential houses built on unstable slopes may suffer partial or complete damage, because landslides can cause instability or damage to the foundation, wall, surrounding facilities, ground and underground facilities of houses. Rock falls may cause damage to travellers and pedestrians. Alpine landslides not only cause casualties and property losses within a certain range, one of the greatest possible hazards should be the impact on traffic. This worldwide impact brings inconvenience to the lives of many people. All types of landslides may cause shortterm or long-term road congestion and inconvenience to commercial transportation, tourism transportation and even emergency transportation, which is a very headache.

Xinchang Huishan Town Xiashan landslide is located in the southwest of basalt platform in Xinchang County, Zhejiang Province (average altitude $375.0 \mathrm{~m}$ ). There were several heavy rainfalls after the landslide slipped in 1989, but it did not induce accelerated sliding. The main reason is that the accumulated energy of the landslide sliding force has been released in 1989, and the landslide may have entered a new stable state after sliding in that year. The accumulated energy of the sliding force is insufficient to promote the accelerated sliding of the landslide. When enough sliding force energy is accumulated, the landslide will continue to slide. The Xiashan slope model is established by computer ( $\mathrm{Yu}$ et al., 2006), and the stability analysis of numerical simulation shows that the landslide is still dominated by creep motion under general conditions. This kind of slope is typical creep stop motion - in the event of sliding landslide disaster. It is of great significance to study the creep development trend of Xiashan landslide for such unstable landslide disasters.

The landslide monitoring and early warning research base was established here by the Zhejiang Provincial Special fund project of basic public strategic geological work in 2019. The Xiashan landslide is a natural landslide without modification and reinforcement. The landslide monitoring project mainly relies on relatively advanced and reliable new technologies such as landslide monitoring instruments and equipment (Zhu et al., 2008; Abraham et al., 2020; Yang et al., 2020), and relies on cloud platform transmission technology based on $3 \mathrm{G} / 4 \mathrm{G}$. In order to achieve the purpose of landslide monitoring and early warning and prediction, a digital monitoring and early warning and popular science education platform integrating monitoring, early warning and prediction release and popular science education training was established. In order to achieve this goal, it is considered to focus on monitoring the surface displacement, deep displacement, groundwater level and rainfall of the landslide, supplemented by video monitoring, early warning broadcasting and manual monitoring in the periphery of the landslide. Based on the landslide survey results and related data of Xiashan Village, Huishan Town, Xinchang County, Zhejiang Province in 2019, this paper describes the geological conditions, the current situation of the landslide and the analysis of the sudden occurrence of the landslide. The historical rainfall data of nearly 30 years in Xinchang County was collected and the future rainfall situation was predicted. The displacement of the Xiashan landslides has been monitored in the past year. The finite element software ANSYS was used to build the slope model considering the rainfall condition, and the stability analysis of the Xiashan landslide was carried out according to the numerical simulation results, and the prevention and control suggestions and measures were put forward.

\section{SLOPE PROFILE}

\section{Status and Characteristics of Landslide}

The landslide is located in Xiashan Village, Huishan Town, Xinchang County, which is an old landslide hazard point. The mountain terrain in the region where the landslide is located is 


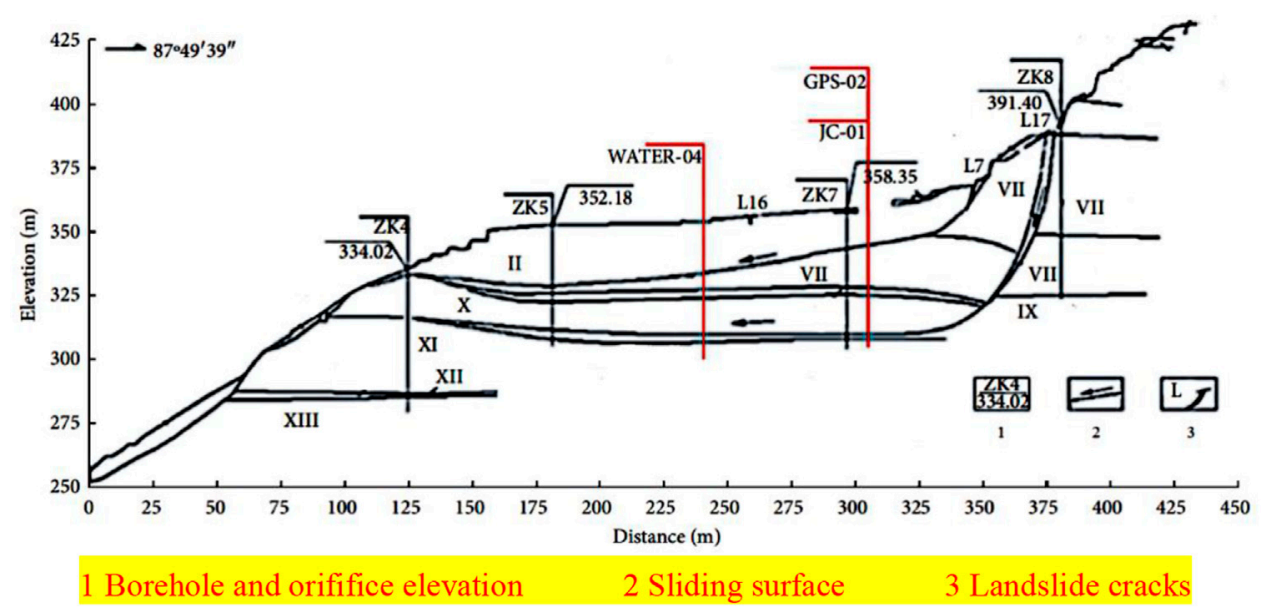

FIGURE 1 | Engineering geological map of typical section.

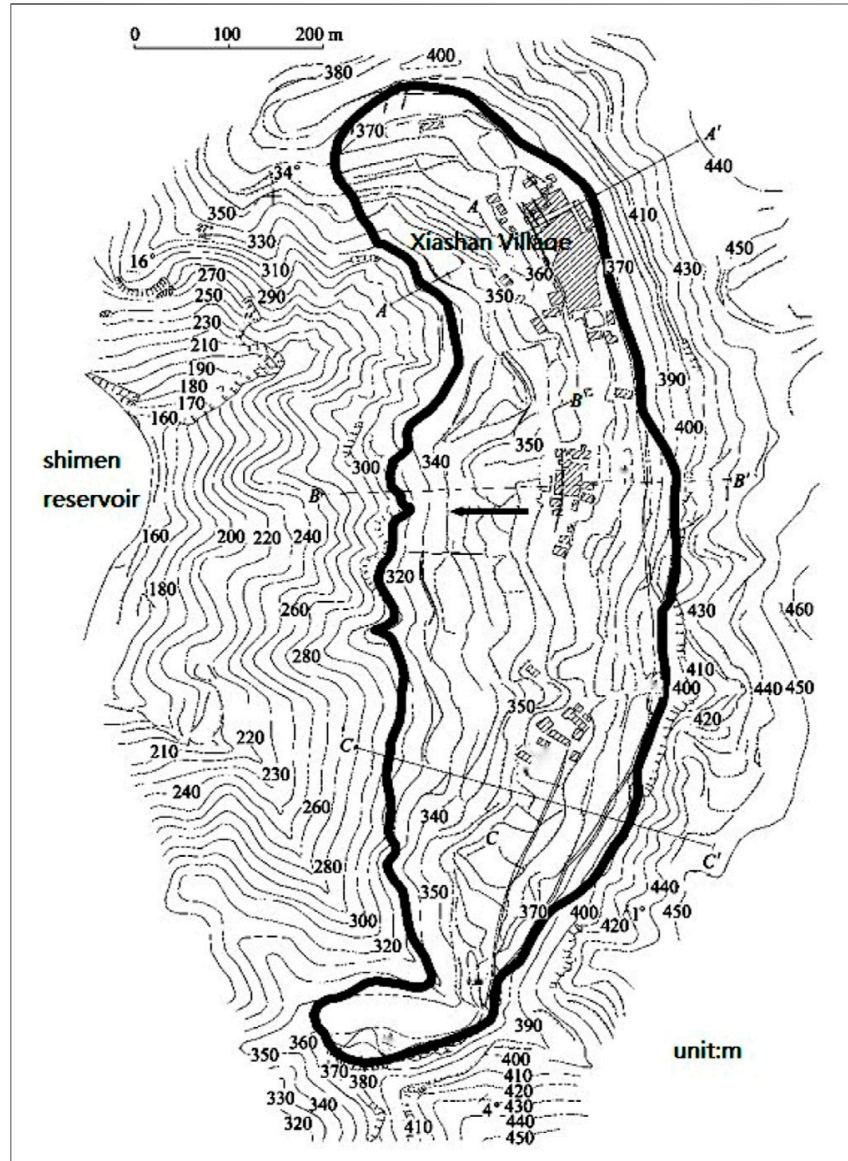

FIGURE 2 | Planar graph of Xiashan landslide.

generally high in the east and low in the west, which has the typical characteristics of a basalt platform. The mountain terrain in the upper part of the platform is relatively flat, with little fluctuation. The highest altitude of the Xiashan landslide area is $507.5 \mathrm{~m}$, the lowest altitude is $121 \mathrm{~m}$, and the relative altitude difference is $386.5 \mathrm{~m}$. The natural terrain is about $15^{\circ}-20^{\circ}$. The terrain in the middle of the platform suddenly becomes steep, and the slope gradient becomes large. The natural terrain slope is generally between $25^{\circ}$ and $50^{\circ}$. The front edge of the platform is usually cut by the valley, showing a deep trench, forming a' $\mathrm{V}^{\prime}$ type valley landform. The bottom is the Shimen Reservoir, with a height difference of more than $200 \mathrm{~m}$, and a strong landscape contrast (Wasowski and Pisano, 2020; Xie et al., 2021). The trailing edge of the landslide and the central terrain slope is relatively gentle, formerly mostly farmland, now because of village relocation, more to dry land, mainly to grow tea and fruit trees, landslide plane Figure 2. The engineering geological conditions of the rock and soil mass in the area vary greatly, and there are many layers, which have the characteristics of typical multiple eruption-sedimentary interbedding and residual slope loose layer thickness. Especially in the Zhutongling Formation of the Shengxian Group of the Upper Pliocene, the sedimentaryeruption cycle is complex, and the diagenesis of each sedimentary layer is extremely poor-very poor. Affected by weather and longterm immersion and infiltration of groundwater, it is mostly soillike and sand-like. The content of local clay minerals and organic matter is high, and the thickness, nature and weathering degree of the basalt eruption zone are significantly different. Therefore, the engineering geological conditions of rock and soil in landslide areas are complex. The joint fissures in the landslide exploration area are relatively developed, and the rocks are strongly weathered and broken. On the basis of the large scale of the original vertical joint fissures in basalt, the rock mass is further opened and the opening width is large, and the rock mass is locally cut into small blocks or large blocks. The joint fissures along the slope in basalt are relatively developed, and some of them have large opening widths. The basic feature of the sliding surface is that the trailing edge is steep, and the sliding surface of the middle leading edge is flat (Figure 1 typical profile). There are mainly two weak structural planes in the landslide. The cracks in the landslide are developed, 


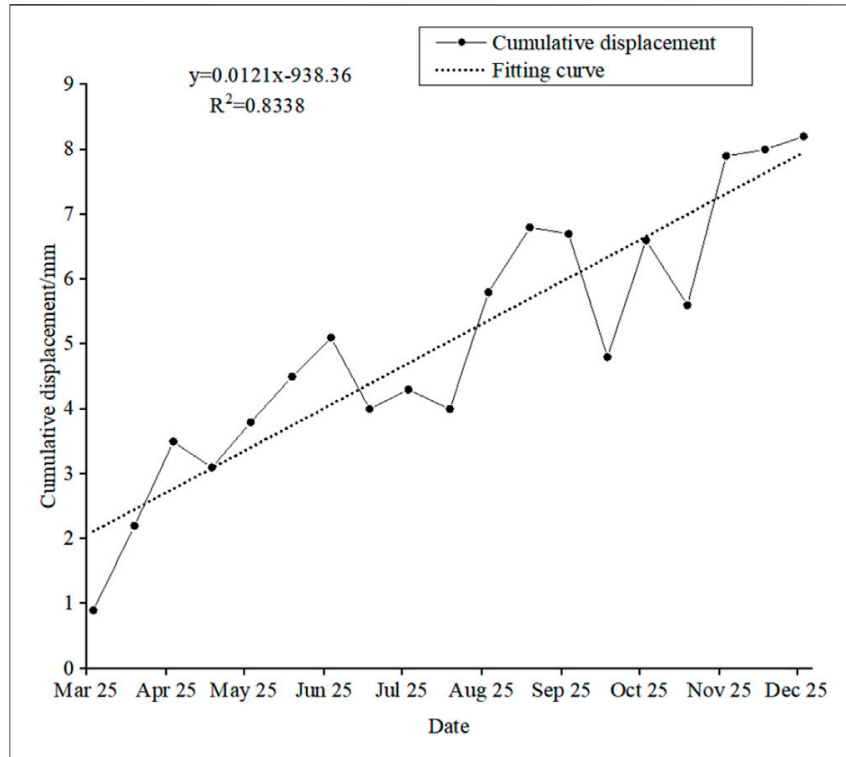

FIGURE 3 | Surface displacement of GPS-02 monitoring point in 2020.

and the landslide is cut into a net shape. There are tension cracks in the trailing edge of the landslide, and the trailing edge of the sliding surface has a large inclination.

According to the exploration operation and the original exploration-related data, the engineering geological conditions of rock and soil mass in the region have changed greatly, and there are many layers, which have the characteristics of typical multiple eruption-deposition interred and thick residual slope accumulation loose layer. Especially in the Zhutongling Formation of the Shengxian Group, the sedimentary-explosive cycle is complex, and the diagenetic range of each sedimentary layer is very poor. Affected by weather and long-term immersion and infiltration of groundwater, it is mostly soil-like and sandy. The content of local clay minerals and organic matter is high. The thickness, nature, and weathering degree of the basalt eruption zone are significantly different. Therefore, the engineering geological conditions of rock and soil in landslide areas are complex.

The Hangzhou-Shaoxing-Taizhou Expressway, a key construction project in Zhejiang Province, is now planned in the Xiashan landslide area. The Hangzhou-Shaoxing-Taizhou Expressway is scheduled to be fully implemented in 2021. Hangzhou-Shaoxing-Taizhou Expressway passes through the Xiashan landslide zone. If a sudden large-scale landslide occurs on the slope, the river channel could be blocked and the highway could be destroyed. It is very harmful to the construction and transportation facilities in mountainous areas, and affects the speed of highway construction.

\section{Landslide Monitoring and Analysis}

The weak structural plane exists in the landslide body, and through drilling exploration, the slope sliding is mainly controlled by two deep and shallow slide zones, and the deep slide zone is the main one, which plays a controlling role. As shown in Figure 1. The deep main sliding zone belongs to the weak interlayer, and below the contact surface of the weak interlayer are the stable and strongly weathered basalt layers. The weak strata are lithologically complex and mainly affected by the sedimentary environment, including sandy clay, clay rock and peataceous soil, etc. There are obvious abrupt changes on the top and bottom of the weak interlayer. According to the supplementary exploration holes, it can be seen that the interlayer is extruding, friction, claying, brecca crushing, and there is Soft plastic-Flow plastic-Soft plastic.

In order to study the current state and development trend of landslides, this paper summarizes the deep displacement and surface displacement of relevant monitoring points near the typical profile of landslides in recent years. Figure 3 shows that the cumulative displacement range of GPS-02 surface displacement monitoring points from March to December 2020 is $1.94-7.7 \mathrm{~mm}$, and the overall trend is increasing over time. The slope is not sliding at present, and the surface displacement is mainly caused by surface floating soil displacement under gravity and rain erosion.

Domestic researchers used the generalized Kelvin model to simulate the creep displacement of the Xiashan landslide ( $\mathrm{Yu}$ et al., 2006). The results show that the cumulative displacement of the Xiashan landslide is $43.87 \mathrm{~mm}$ after 20.89 months. As shown in Figure 4, this paper fitted and predicted the deep displacement of the slope after about 14 years of the generalized Kelvin model and the general creep landslide. The results showed that the cumulative displacement of the former was about $60.8 \mathrm{~mm}$, and with the passage of time, the annual cumulative displacement gradually decreased, and the annual cumulative displacement was only about $0.6 \mathrm{~mm}$ from June 2020 to June 2021. The cumulative displacement of the latter is about $162.3 \mathrm{~mm}$, and the cumulative displacement from June 2020 to June 2021 is about $9.5 \mathrm{~mm}$. From June 2020 to June 2021 , the cumulative displacement value at $30.5 \mathrm{~m}$ underground of the JC-01 deep displacement monitoring point of the Xiashan landslide fluctuated between -0.6 and $0.0 \mathrm{~mm}$ with time. Taking into account factors such as the accuracy of monitoring instruments and the difficulty of field monitoring, the slope does not produce negative displacement. Based on the above monitoring data, it is concluded that the Xiashan slope is different from the general creep landslide. The deep sliding zone that plays a controlling role will continue to move over time at the beginning, but the displacement decreases year by year, and finally approaches zero, basically in a non-sliding state. If the landslide is affected by rainfall, the slope stability will be further reduced, and the accumulated energy is sufficient to produce rapid sliding.

In this paper, based on the research on the prediction method of potential locking landslide (Pan et al., 2014; Yin et al., 2021), the locking property of Xiashan landslide in Xinchang County, Zhejiang Province is as follows: the slope of Xiashan landslide is $15^{\circ}-45^{\circ}$; the lithology of the strata is mostly soil and sand, and the content of local clay minerals and organic matter is high. The strata occur in the gently inclined slope and the dip angle is less than the slope angle. The front landslide is sliding and extruded, and the trailing edge has tensile cracks. The region belongs to the subtropical monsoon climate area. The overall temperature is warm and humid, and the rainfall is abundant. The seismic activity intensity is low, the magnitude is small and 


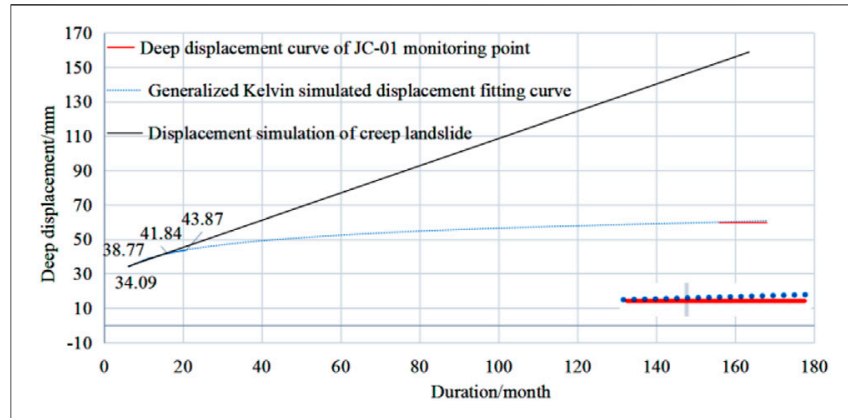

FIGURE 4 | Cumulative deep displacement duration curve of B-B

section

the frequency is low in Xinchang County. This kind of landslide is composed of multiple rocks and soil layers and distributed according to a certain layer occurrence. Under the action of static aging or dynamic vibration deformation, the stress concentration in the locking section of the potential sliding surface. When the locking section is not connected, even if the landslide produces a creeping phenomenon, it will not immediately cause overall instability and lead to landslide hazard. However, when the slope accumulates sufficient sliding force energy, it will lead to the high-speed start of the landslide. This sudden hazard is often beyond prevention. According to the formation conditions and characteristics of various landslides, it is consistent with the formation conditions of a locking landslide, and it can be preliminarily determined that this slope is a locking landslide with potential static aging deformation instability.

\section{Theoretical Stability Calculation of Control Slip Band}

When a landslide occurs failure along the existing sliding surface, landslide stability analysis is often based on limit equilibrium theory. The sliding surface can be approximately simplified as a broken line. The transfer coefficient method is used to solve the remaining sliding force and stability evaluation. According to the shape of the broken line, the landslide body is divided into several sections. The sliding force is transferred along the direction of the sliding surface. The overall remaining sliding force can be calculated and the stability of the landslide can be judged (Liu et al., 2009). According to the characteristics of bedding creep failure of the Xinchang Xiashan landslide, the bedding landslide under creep mode is taken as the research object. The terrain line and sliding zone of the landslide are simplified as broken lines (Figure 5). The specific calculation method of the calculation model is as Eq. 1-4. The calculation results are shown in Table 1.

$$
K_{f}=\frac{\sum_{i=1}^{n-1}\left(R_{i} \prod_{j=i}^{n-1} \psi_{j}\right)+R_{n}}{\sum_{i=1}^{n-1}\left(T_{i} \prod_{j=i}^{n-1} \psi_{j}\right)+T_{n}}
$$

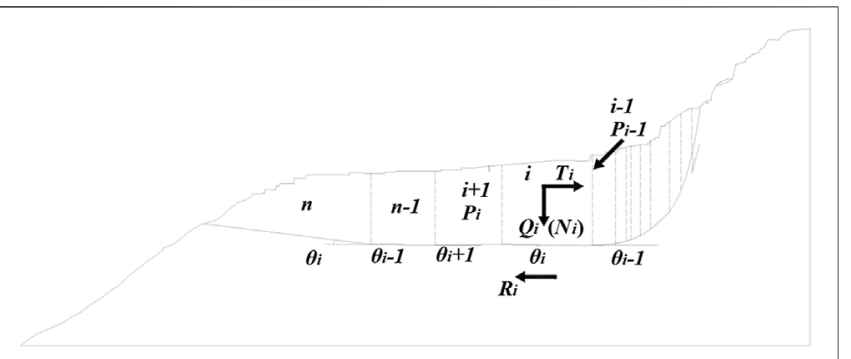

FIGURE 5 | Calculation diagram of transfer coefficient method.

$$
\begin{aligned}
& \text { CH2O: } \\
& R_{i}=\left(W_{i}\left(\left(1-r_{U}\right) \cos \alpha_{i}-A \sin \alpha_{i}\right)-R_{D i}\right) \tan \varphi_{i}+C_{i} L_{i} \\
& T_{n}=\left(W_{i}\left(\sin \alpha_{i}+A \cos \alpha_{i}\right)\right)+T_{D i} \\
& \prod_{j=i}^{n-1} \psi_{j}=\psi_{i} \psi_{i+1} \psi_{i+2} \ldots \ldots \ldots \psi_{n-1} \\
& \psi_{i}=\cos \left(\alpha_{i}-\alpha_{i+1}\right)-\sin \left(\alpha_{i}-\alpha_{i+1}\right) \tan \varphi_{i+1} \\
& \text { CH2O: } K_{f} \text {-Landslide stability coefficient; } \\
& \psi_{i}-\text { Coefficient } \\
& \quad \text { transmission; } \\
& \quad \Psi=\cos \left(\beta_{n-1}-\beta_{n}\right)-\sin \left(\beta_{n-1}-\beta_{n}\right) \tan \varphi_{n} \\
& R_{i}-\text { Section i Calculation of Slip Resistance of Strip Block } \\
& \quad(\mathrm{kN} / \mathrm{m}) ;
\end{aligned}
$$

Calculation of landslide stability coefficient by following formula.

$$
\begin{aligned}
& T_{n}=T_{n-1} \psi+A \gamma \sin \beta_{n}+D_{i} \cos \left(\beta_{n}-\alpha_{n}\right) \\
& R_{n}=R_{n-1} \psi+A \gamma \cos \beta_{n}+D_{i} \sin \left(\beta_{n}-\alpha_{n}\right) \tan \varphi_{n}+c_{n} l_{n} \\
& F_{s}=\frac{R_{n}}{T_{n}}
\end{aligned}
$$

CH2O: $\gamma$-Weighted average gravity;

$A$-Section area of sliding body, $\mathrm{m}^{2} ; T_{n}$ and $T_{n-1}-$ The remaining sliding force of block $\mathrm{N}$ and block $\mathrm{N}-1$; $\psi$-Coefficient of transmission;

$\varphi_{n}, c_{n}$-The standard value of friction Angle and cohesion of the sliding body in block $\mathrm{N}$ along the sliding surface;

$l_{n}$-Length of block $\mathrm{N}$ sliding body along the sliding surface;

$D_{i}$-Water penetration, $D_{i}=r_{\omega} A \sin \alpha_{i}=F_{i} \sin \alpha_{i}$, A is the soil area under the water level line, $\alpha_{i}$ is the inclination of water surface, $\beta_{i}$ is the inclination angle of landslide.

According to the stability calculation in Table 1, the stability of the deep sliding zone is significantly lower than that of the shallow sliding zone. The landslide has two sliding zones, shallow and deep, and the deep sliding zone is the main one, which plays a controlling role. It can be seen that the landslide is a typical longterm slow deformation in the free direction by means of the gravity of the soil itself. Due to the large range of landslide distribution, and irregular character, under normal conditions, the possibility of overall speed skating is not large. The 
TABLE 1 | Calculation results of landslide stability.

\begin{tabular}{llc}
\hline & $\begin{array}{c}\text { Calculated work } \\
\text { condition }\end{array}$ & $\begin{array}{c}\text { Coefficient of } \\
\text { stability }\end{array}$ \\
\hline $\begin{array}{l}\text { Typical section of Xiashan } \\
\text { landslide }\end{array}$ & $\begin{array}{l}\text { Shallow sliding zone } \\
\text { Deep slide zone }\end{array}$ & 1.571 \\
\hline
\end{tabular}

exploration area is located in the subtropical monsoon climate zone. It is generally warm and humid, with abundant rainfall. During persistent rainfall or heavy rainfall, the local sliding speed of the leading edge will accelerate and the slope stability will be greatly reduced.

The geological environment conditions of the three natural villages in Yuanxiashan, Lishan and Tang (Yin et al., 2021), which are involved in the range of Xiashan landslide area, become more fragile under the action of human engineering activities. The free surface formed by topographic and geomorphologic conditions provides sufficient unloading space for the landslide. There are a large number of clay groups in the soft rock strata, and the mechanical properties are significantly lower than those of clay rocks and argillaceous siltstone in the upper and lower rock strata. Mudstone, clay rock, argillaceous shale, silty clay rock and argillaceous siltstone are common in soft rock strata. Most of them belong to soft rock with uniaxial compressive strength of less than $30 \mathrm{MPa}$. The weak interlayer refers to the soft rock stratum with low mechanical strength, high clay or carbon content, easy softening of rainwater, long extension and thin thickness. A mudded interlayer refers to the part of the weak interlayer and weak rock layer that has been modded. It is a shear smooth surface or soft rock surface formed by interlayer dislocation, which is ground by hard rock, and soaked and softened by groundwater, so that the material composition of rock powder changes into viscoplastic soft mud. Good joint crack connectivity, rock fragmentation, accelerated groundwater activity; strong rainfall has formed seepage channels in landslides; natural gullies have been scouring the slope during rainfall. From the perspective of the whole geological environment, the slope has the geological conditions for landslides.

The landslide has had three large slides since 1958. The frequent activities in the past 40 years are closely related to the reclamation and deforestation of human beings and the opening of irrigation channels around mountains. Human activities have accelerated soil erosion, increased the large amount of rainwater and surface irrigation, infiltrated into the aquifer in the landslide, lubricated and softened the deep rock and soil mass (landslide), and directly destroyed the stability of the natural slope. Induced by sliding in 2000, although one-time (daily) precipitation intensity is not large, the sliding force energy accumulation has reached the induced limit point, so the sliding. The deformation failure mode is the creep-cracking type, as shown in Figure 6. Due to the fact that the rock and soil of the landslide are broken and there are many cracks on the surface, as the rainwater on the slope invades the interior of the slope, the groundwater level is greatly improved, which aggravates the weakening of the properties of the rock and soil, and the

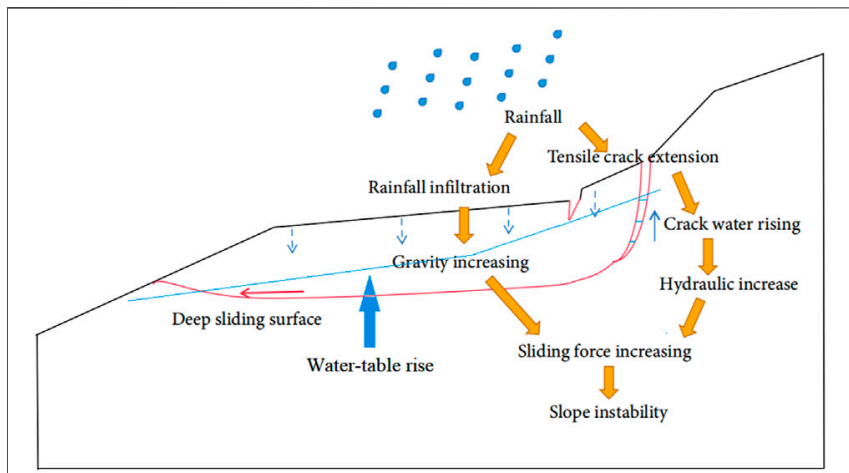

FIGURE 6 | Schematic of hydraulic driving type.

rainwater has a lag in the interior of the slope. It increases the self-weight of the slope in a short time, increases the hydrostatic pressure and hydrodynamic pressure in the slope, and the energy of the sliding force continues to increase. Rainfall reduces the shear strength of the sliding zone. Under the action of self-weight, the landslide begins to slide toward the free surface (Stark and Xu et al., 2020; Zhu et al., 2020).

As shown in Figure 6, In the process of continuous accumulation of groundwater on the sliding surface, the shear stress on the sliding shear surface is concentrated. After the landslide occurred in 2000, the surface cracks at the trailing edge of the landslide increased and the number of cracks increased sharply, resulting in more surface water invading the slope along the tensile cracks at the trailing edge, accelerating the creeping process, and weakening the shear strength of the shear surface, so as to promote the landslide again to the leading edge. Finally, the leading edge of the landslide was completely sheared and the landslide phenomenon occurred. Due to the long-term immersion of the sliding zone by groundwater, the sliding body showed plastic flow characteristics.

Because there is a "bowl-like" structure on the front edge of sliding, it can well resist the impact of sliding, which is the main reason why the landslide has had several strong rainfalls after sliding, but does not induce accelerated sliding. Although the' bowl' structure can prevent the slope from sliding in a short time, it also causes the accumulation of landslide sliding force energy. When the accumulation of sliding force energy has reached the induced limit point, it will slide again. When the groundwater level increases, the self-weight of water increases the energy of sliding force and accelerates the formation of landslides. On the one hand, the lubrication of water reduces the matric suction and cohesion between soil particles. On the other hand, the buoyancy generated by the increase in groundwater level supports soil particles, which makes the sliding force transmitted from the trailing edge easier to promote the slip of the soil layer.

\section{RAINFALL HISTORY STATISTICS}

The landslide has had three major slides since 1958. From the cause, the main factors are as follows: first, the frequent 
TABLE 2 | Statistical table of typhoons affecting rainfall in Xinchang county from 1990 to 2021.

\begin{tabular}{lcc}
\hline Name of typhoon & Start and end dates & Daily rainfall/(mm) \\
\hline Abe & $1990 / 8 / 31-1990 / 9 / 1$ & 110.3 \\
Ted & $19,929 / 23-1992 / 9 / 24$ & 125.8 \\
Rananim & $2004 / 8 / 13$ & 141 \\
Khanun & $2005 / 9 / 11$ & 153.6 \\
Krosa & $2007 / 10 / 7-2007 / 10 / 8$ & 134.7 \\
Fitow & $2013 / 10 / 7-2013 / 10 / 8$ & 134.9 \\
Lekima & $2019 / 8 / 10-2019 / 8 / 11$ & 221 \\
Mitag & $2019 / 10 / 2-2019 / 10 / 3$ & 101.5 \\
In-fa & $2021 / 7 / 24-2021 / 7 / 25$ & $200-250$
\end{tabular}

activities in the past 40 years are closely related to human's reclamation and deforestation, the development of irrigation channels around mountains, and human activities accelerate soil erosion. Second, the leading edge of the landslide is mostly cliff or steep slope, and the landslide body is in the air state. However, because the rock layer in the landslide is nearly horizontal, the sliding surface of the leading edge of the landslide is not inclined, and the sliding momentum of the landslide body is not large, and stagnation often occurs after a slip. Third, under the influence of continuous rainfall or heavy rain, surface irrigation water infiltrates into the aquifer of the landslide body, lubricating and softening the deep rock and soil mass (landslide), and directly damaging the stability of the natural slope locally (Bontemps et al., 2020; Løvholt et al., 2020).

There were several heavy rainfalls after landslide sliding in 1989, but no accelerated sliding was induced. The main reason was that the accumulated energy of landslide sliding force had been released in 1989. The insufficient accumulated sliding force energy promoted the accelerated sliding of landslides. When sufficient sliding force energy was accumulated and lubrication was sufficient, the landslide continued to slide. For example, the sliding induced in 2000, although one-time (daily) rainfall intensity is not large, the energy accumulation of the sliding force has reached the induced limit point, so the sliding occurs again. It is speculated that the sliding of the Xiashan landslide is intermittent and delayed.

The front edge of the landslide is worse than the rear edge, and the aquifer in the middle and rear part of the landslide is thick. In rainy season, a natural underground water storage site is often formed with the front of the landslide as the earth-rock dam, and the middle and rear parts and the rear edges as water bodies. Strongly weathered sandy soil mixed with silty clay basalt contains more pore water, locally under the action of strong rock and soil sliding force was grinded into glue, thin layer containing water. Quaternary gravel layer, sedimentary rock sand (gravel eggs) stone layer and basalt fracture development permeability is good. Groundwater is rich, seasonal variation.

The precipitation in landslide areas mainly concentrated in the typhoon period and meiflood rainy season, and short-term or continuous heavy precipitation often occurred, which promoted the formation and induction of landslides. In this paper, the number of heavy rains (daily rainfall $>100 \mathrm{~mm}$ ) in xinchang

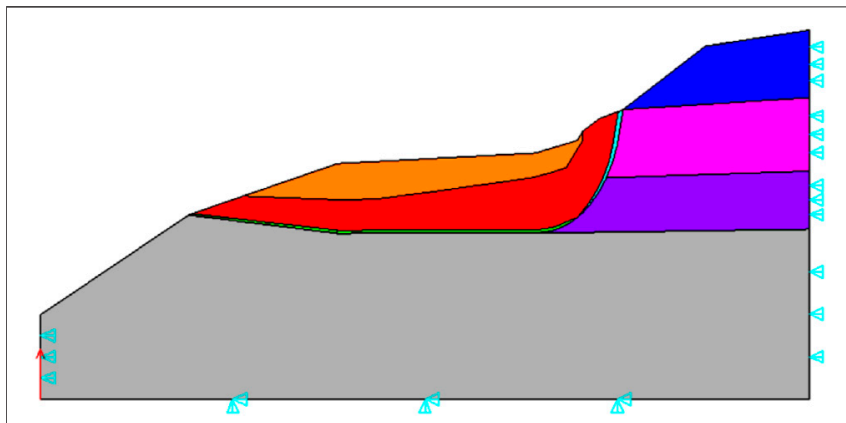

FIGURE 7 | Calculation model of Xiashan landslide in Xinchang.

county in recent 30 years was counted, among which 9 days were obviously affected by typhoons. As can be seen from Table 2, the average daily rainfall in 9 days is $149.76 \mathrm{~mm}$, and the process rainfall can reach 200-500 mm (Huang et al., 2021).

Data from Table 2 show that the frequency and intensity of rainstorms caused by typhoons have increased in recent years, which may lead to persistent rainfall and flood disasters (Huang et al., 2021). According to rainfall statistics from several stations in Shaoxing at 15: 00 p.m. on July 24, 2021, the 12-h rainfall total exceeded $200 \mathrm{~mm}$. Care should be taken to prevent existing water and drainage facilities from adapting to increased rainfall each year.

\section{LANDSLIDE STABILITY PREDICTION}

\section{The Slope Model}

Through geological exploration and investigation, the twodimensional landslide calculation model of the Xiashan landslide is established, as shown in Figure 7. Ansys modelling was used for numerical simulation, and the slope changes caused by continuous rainfall were analyzed in detail. Five rainfall conditions were analyzed, and compared. Working Condition 1: gravity + dry groundwater level; Working condition 2: gravity + low groundwater table; Working condition 3: gravity + normal groundwater level; Working condition 4: gravity + high groundwater table; Working condition 5: gravity + highest groundwater level.

A typical profile consistent with the main sliding direction of the Xiashan landslide is selected as an example for SRM (strength reduction method) analysis. The advantage of this method is that the dangerous sliding surface of the slope is automatically obtained by the program without assuming the shape and position of the sliding surface (Zhao et al., 2002; Gao et al., 2020). The physical and mechanical parameters of landslides adopted by the model (Table 3 ).

\section{Stability Calculation and Analysis}

Figure 8 shows the total displacement of the sliding body on the deep sliding surface of the landslide under normal circumstances. The total displacement and horizontal displacement of the sliding body are usually the largest at the trailing edge. The sliding displacement along the sliding surface decreases from the back 
TABLE 3 | Mechanical parameters of rock and soil.

\begin{tabular}{|c|c|c|c|c|c|}
\hline Structural layer & $\begin{array}{l}\text { Elastic modulus } \\
\qquad E(\mathrm{MPa})\end{array}$ & $\begin{array}{c}\text { Poisson's ratio } \\
\mu\end{array}$ & $\begin{array}{c}\text { Volumetric weight } \\
\qquad \gamma\left(\mathrm{kN} / \mathrm{m}^{3}\right)\end{array}$ & $\begin{array}{c}\text { Cohesion intercept } \\
\qquad \text { c (kPa) }\end{array}$ & $\begin{array}{c}\text { Angle of } \\
\text { internal friction } \\
\varphi\left({ }^{\circ}\right)\end{array}$ \\
\hline Sliding mass & 15 & 0.33 & 19.7 & 37 & 22 \\
\hline Weak Interlayer & - & - & - & 10 & 7 \\
\hline Strata III-IX & 4,000 & 0.23 & 21 & - & - \\
\hline Stratum X & 5,000 & 0.21 & 22 & - & - \\
\hline
\end{tabular}

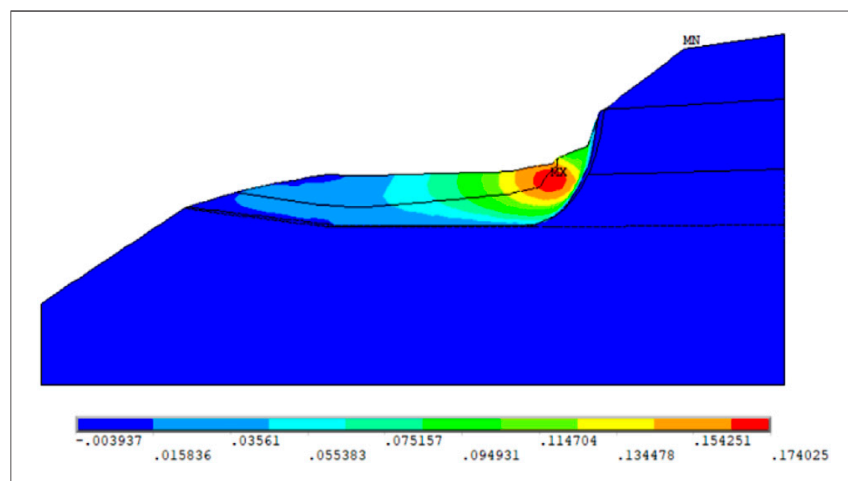

FIGURE 8 | Displacement value diagram of sliding body in deep sliding surface of Xiashan section.

edge to the front edge and decreases rapidly when the sliding surface changes from gentle to locked section. Figure 9 shows five types of the slope under the condition of effective plastic strain figure, the figure shows the main strain inside the sliding body to focus on the rear of the deep slip band contact belt, slope is mainly controlled by two sliding surface, under the action of heavy rainfall and groundwater seepage of deep rock mass near weak structural plane prone to plastic deformation, and the trailing edge is relatively obvious in landslide, The maximum thickness of the sliding body is about $60.0 \mathrm{~m}$, and the average thickness is about $34.25 \mathrm{~m}$. Rainfall intensity has a great influence on the slope plastic zone. With the gradual increase of rainfall intensity, the slope plastic zone first accumulates energy at the back edge. When the energy is enough to push the locked section, the rock mass in the plastic zone is prone to drastic sliding. If cracks appear below or above the slope slip surface or are damaged artificially, the sliding surface may develop towards the failure of weak cracks, Thus, the plastic zone of the landslide is no longer through the original slip zone. The results of simulation show that, with the continuous infiltration of rain, the slope weight increases, the matrix suction and shear strength decrease, and the soil at the back edge of the slope continues to settle. Due to the continuous infiltration of rainwater from the slope surface and the continuous aggregation of pore water at the back edge of the slope, the strength of the soil at the front edge of the slope is significantly reduced, which does not provide enough skid resistance, and the overall instability of the slope will occur at last.

The calculation results of the Mohr-Coulomb hexagon circumcircle yield criterion (DP1) used in Ansys software are different from those of the traditional Mohr-Coulomb criterion. In order to make the slope safety factor obtained by the finite element strength reduction method consistent with the safety factor used in traditional engineering practice, the plane strain Mohr-Coulomb matching D-P criterion is adopted (Zheng and Zhao et al., 2005). Eq. 5-7 are shown below.

$$
\begin{gathered}
c_{i}=\frac{c}{F_{i}} \\
F_{2}=\sqrt{\frac{\tan \varphi_{i}=\frac{\tan \varphi}{F_{i}}}{\left(3 \sqrt{\cos ^{2} \varphi_{0} F_{i}^{2}+\sin ^{2} \varphi_{0}}-\sin \varphi_{0}\right)^{2}-12 \sin ^{2} \varphi_{0}}}
\end{gathered}
$$

Where $C$ is the standard value of bond strength $(\mathrm{kPa})$ of rock and soil mass on the sliding surface; $\varphi$-standard value of internal friction Angle of sliding belt soil $\left({ }^{\circ}\right)$; Fi-Strength reduction coefficient; Safety factor of F2-mol-Coulomb matching with D-P criterion.

Table 4 and Figure 10 show that the slope safety factor decreases with the increase in rainfall intensity. When the groundwater level is normal, the rainwater infiltrates into the shallow soil, and the increase in the saturation of the shallow soil leads to the decrease of the shear strength and safety factor of the slope. The slope is mainly controlled by the shallow sliding surface. When the rainfall intensity increases, the rainwater infiltration rate increases, and the rainwater infiltrates into the deep soil. The groundwater level increases. The landslide begins to be affected by the deep sliding zone, and the dangerous sliding surface of the slope turns to the deep sliding surface. At this time, the share strength of the slope decreases significantly, and the attenuation of the slope safety factor is the largest. When the rainfall infiltration rate reaches the maximum, the soil tends to be saturated, the shear strength is close to the minimum, and the decline trend of slope safety factor is gradually flat. Therefore, the landslide is actually controlled by the deep sliding surface. When the groundwater level reaches the highest, the slope safety factor reaches the lowest, and the slope is in an unstable state.

The slope safety factor range is 1.039-1.168. When the groundwater level is high, the slope safety factor is greater than 1.05, and the slope is basically stable. When the groundwater level reaches the highest, the slope safety factor is less than 1.05, and the slope is unstable. Therefore, the landslide is 


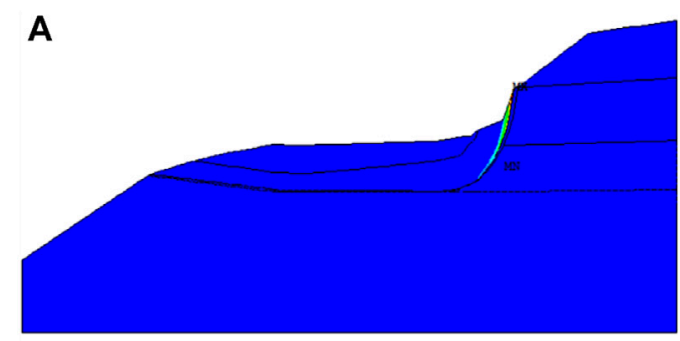

Plastic strain diagram of working condition 1

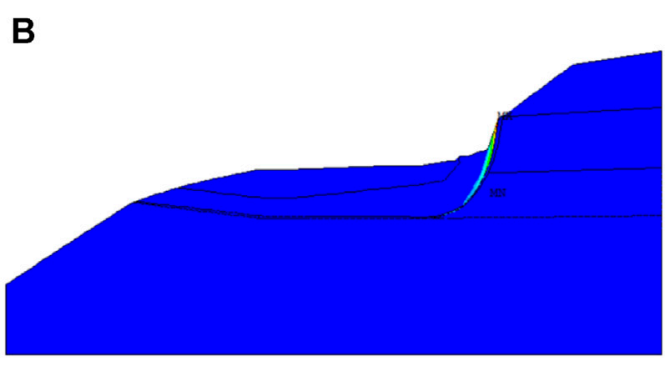

Plastic strain diagram of working condition 2

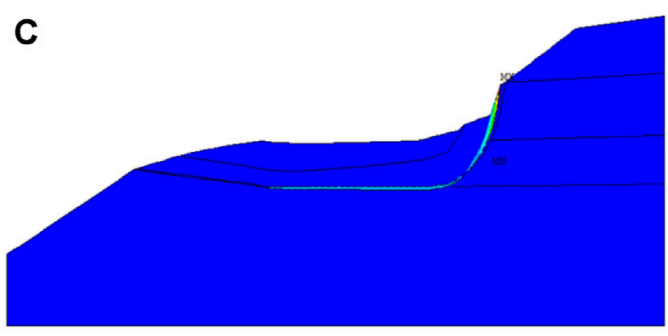

Plastic strain diagram of working condition 3

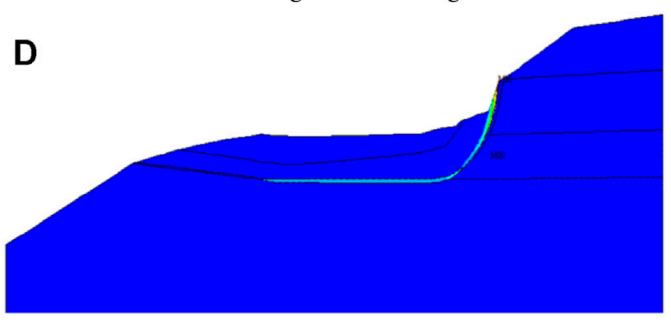

Plastic strain diagram of working condition 4

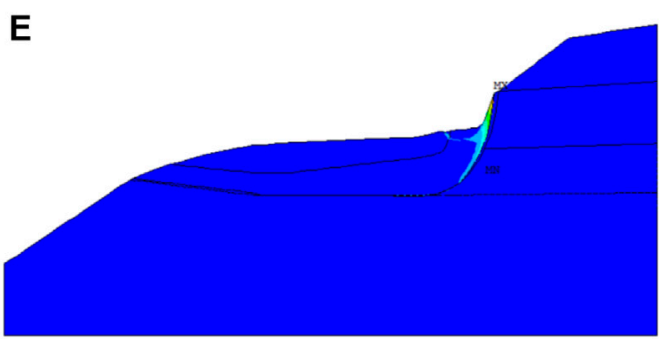

Plastic strain diagram of working condition 5

FIGURE 9 | Plastic strain diagram of working conditions 1-5.

basically stable on the whole. When encountering heavy rain, it is in an unstable state, and the creep speed of the slope will gradually increase. When the locking section accumulates sufficient sliding
TABLE 4 | Slope safety coefficient in five working conditions.

\begin{tabular}{lccccc}
\hline & Model 1 & Model 2 & Model 3 & Model 4 & Model 5 \\
\hline Factor of safety & 1.168 & 1.133 & 1.078 & 1.052 & 1.039
\end{tabular}

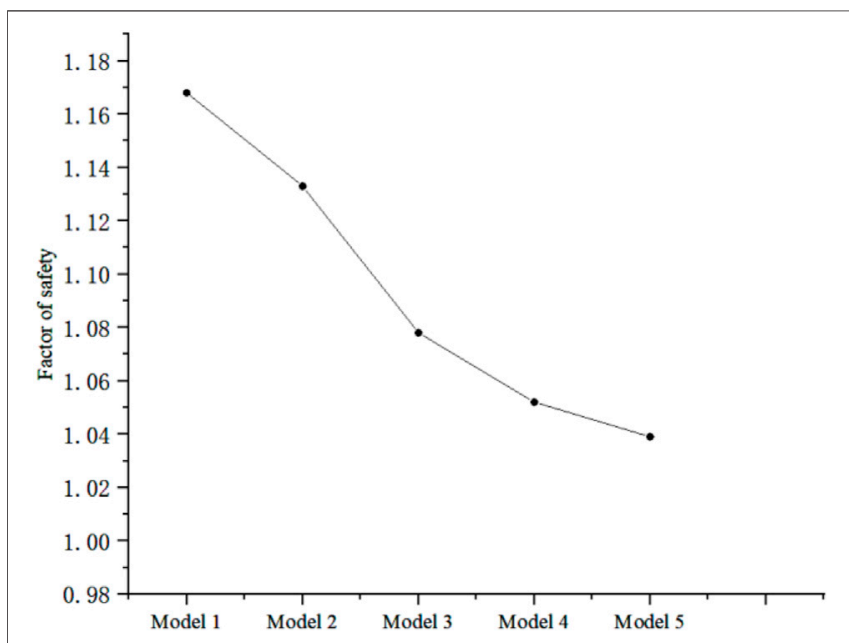

FIGURE 10 | Variation diagram of slope stability coefficient with different rainfall intensity.

force energy, it may lead to the high-speed start of a landslide, which will cause harm to the buildings in the downstream area of the Xiashan slope, and even threaten the safety of people.

\section{SUGGESTIONS OF PREVENTION AND CURE}

The treatment of such landslides should be early detection and prevention first. In order to deal with working conditions such as heavy rain that significantly affects the safety of the slope, drainage should be set up on the slope. When necessary, comprehensive treatment schemes such as slope cutting at the top of the slope, slope toe retaining, and reinforcement in the middle of the landslide are adopted. The specific recommendations are as follows:

1) In the past 10 years, the slip velocity of the landslide front was 36-77 mm/a, and the accurate sliding time and sliding range of the landslide are uncertain. Excavating large-section intercepting ditches on the stable stratum outside the slope top effectively prevents surface water from entering the landslide area. Increase the number of drainage ditches on landslide surface, increase drainage ditch section, and accelerate surface water drainage.

2) The front, rear edge and surface cracks of the slope are filled with waterproof and impermeability materials. Increase the density of underground drainage facilities such as seepage ditches, blind ditches, drainage holes and collecting wells. 
3) If technical measures are taken to strengthen the slope in the later stage, the height of the slope instability can be reduced by slope cutting and load reduction. In addition, anti-slide piles, retaining walls, bolts, anchor cables and other reinforcement components can be reasonably arranged to improve the stability of slope soil.

4) Regular inspection and maintenance of slope waterproof and drainage facilities and reinforcement measures.

\section{CONCLUSION}

1) There are mainly two weak structural planes in the landslide. The fracture of landslides is developed, the development of weak structural planes is poor, and the landslides are cut into a net shape. There are tension cracks at the trailing edge of the landslide, which are not conducive to slope stability.

2) The landslide generally moves along the sliding zone, but the existence of the locking section curbs the creep displacement, and the slope will accumulate energy. When the slope is artificially damaged, resulting in the generation or intensification of cracks, the plastic zone of the landslide may develop to a weak point and no longer move along the sliding zone.

3) The field monitoring results show that the slope is basically in a static state. The numerical model calculation results show that when the groundwater level reaches the highest, the stability coefficient is less than 1.05, and the slope creep begins to intensify, and the slope is in an unstable stage.

4) In general, the follow-up landslide is basically static, and the overall slip is small. The main displacement is concentrated on the surface floating soil movement. In the case of heavy rainfall, when the energy gathered by the slope is greater than the anti-sliding force, it may lead to accelerated creeping of the slope until the landslide starts at high speed.

5) The results of the slope numerical model show that rainfall has an important influence on slope stability. Under normal conditions, the tensile stress at the top of the trailing edge of the landslide is close to its saturated tensile strength. If

\section{REFERENCES}

Abraham, M. T., Satyam, N., Bulzinetti, M. A., Pradhan, B., Pham, B. T., and Segoni, S. (2020). Using Field-Based Monitoring to Enhance the Performance of Rainfall Thresholds for Landslide Warning. Water 12 (12), 3453. doi:10.3390/ w12123453

Bontemps, N., Lacroix, P., Larose, E., Jara, J., and Taipe, E. (2020). Rain and Small Earthquakes Maintain a Slow-Moving Landslide in a Persistent Critical State. Nat. Commun. 11 (1), 780. doi:10.1038/s41467-020-14445-3

Gao, F., Li, X. J., and Chi, M. J. (2020). Analysis of Stability of Single and Double Side Soil Slopes with FEM Strength Reduction Method. J. Eng. Geol. 28 (3), 650-657. doi:10.13544/j.cnki.jeg.2018-080

Guang, S., Mao, Z. L.-r., Zhen-gao, L. K.-d. C., and En-kun, M. (2008). The Geological Characteristics and Stability Analysis of the Xiashan Village Landslide in Xinchang County, Zhejiang Province. Chin. J. Geol. Hazard. Control. 4. doi:10.3969/j.issn.1003-8035.2008.04.004

He, K. Q., Chen, W. G., and Zhang, P. (2016). Real-time Monitoring of Dynamic Stability Coefficient and Displacement Criterion of the Creep Slope. Chin. J. Rock Mech. Eng. 35 (7), 1377-1385. doi:10.13722/j.cnki.jrme.2015.1535 heavy rainfall occurs, the tensile stress at the top of the trailing edge exceeds the saturated tensile strength, which will lead to tensile cracks, and the cracks will gradually expand over time and affect the stability of the slope.

6) This kind of risk is high, with delay and intermittency. When it comes to external factors such as rainstorm and artificial activities, it will suddenly explode. It is not easy to determine immediately that landslides should be monitored and predicted for a long time, and the water treatment is mainly based on a variety of drainage measures. When necessary, the slope can be comprehensively treated.

\section{DATA AVAILABILITY STATEMENT}

The original contributions presented in the study are included in the article/Supplementary Material, further inquiries can be directed to the corresponding author.

\section{AUTHOR CONTRIBUTIONS}

All authors listed have made a substantial, direct, and intellectual contribution to the work and approved it for publication.

\section{FUNDING}

The study was funded by the National Natural Science Foundation of China (Grant Nos. 42077251 and 41807269). The work presented in this paper was also supported by Open Research Fund of State Key Laboratory of Geomechanics and Geotechnical Engineering, Institute of Rock and Soil Mechanics, Chinese Academy of Sciences (Grant No. Z020011), Fundamental Research Funds for the Central Universities (Grant No. DUT20RC (3)011), Collaborative Innovation Center for Prevention and Control of Mountain Geological Hazards of Zhejiang Province (PCMGH-2016-Z-04).
Huang, Y., Sun, Z., Bao, C., Huang, M., Li, A., and Liu, M. (2021). A Typical Basalt Platform Landslide: Mechanism and Stability Prediction of Xiashan Landslide. Adv. Civil Eng. 2021, 1-14. doi:10.1155/2021/6697040

Kaya, A., and Midilli, Ü. M. (2020). Slope Stability Evaluation and Monitoring of a Landslide: a Case Study from NE Turkey. J. Mt. Sci. 17 (11), 2624-2635. doi:10.1007/s11629-020-6306-x

Li, S.-Y., Li, D.-D., Liu, H.-D., Wang, S.-W., Geng, Z., and Peng, B. (2021). Formation and Failure Mechanism of the Landslide: a Case Study for Huaipa, Western Henan, China. Environ. Earth Sci. 80 (15), 1-12. doi:10.1007/s12665021-09781-6

Lin, Q., Wang, Y., Glade, T., Zhang, J., and Zhang, Y. (2020). Assessing the Spatiotemporal Impact of Climate Change on Event Rainfall Characteristics Influencing Landslide Occurrences Based on Multiple GCM Projections in China. Climatic Change 162 (2), 761-779. doi:10.1007/s10584-020-02750-1

Liu, C. H., Jaksa, M. B., and Meyers, A. G. (2009). A Transfer Coefficient Method for Rock Slope Toppling. Can. Geotech. J. 46 (1), 1-9. doi:10.1139/t08-094

Løvholt, F., Glimsdal, S., and Harbitz, C. B. (2020). On the Landslide Tsunami Uncertainty and hazard. Landslides 17, 2301-2315. doi:10.1007/s10346-020$01429-\mathrm{z}$ 
Marin, R. J., and Velásquez, M. F. (2020). Influence of Hydraulic Properties on Physically Modelling Slope Stability and the Definition of Rainfall Thresholds for Shallow Landslides. Geomorphology 351, 106976. doi:10.1016/ j.geomorph.2019.106976

Marino, P., Peres, D. J., Cancelliere, A., Greco, R., and Bogaard, T. A. (2020). Soil Moisture Information Can Improve Shallow Landslide Forecasting Using the Hydrometeorological Threshold Approach. Landslides 17 (9), 2041-2054. doi:10.1007/s10346-020-01420-8

Naidu, S., Sajinkumar, K. S., Oommen, T., Anuja, V. J., Samuel, R. A., and Muraleedharan, C. (2018). Early Warning System for Shallow Landslides Using Rainfall Threshold and Slope Stability Analysis. Geosci. Front. 9 (6), 1871-1882. doi:10.1016/j.gsf.2017.10.008

Pan, X. H., Xue, L., Qin, S. Q., Li, G. L., Pei, L., and Wang, M. M. (2014). Types, Formation Conditions and Pre-decision Method for Large Landslides with Potential Locked Patches. J. Eng. Geol. 22 (6), 1159-1167. doi:10.13544/j.cnki.jeg.2014.06.021

Ramesh, G. (2021). Slope and Landslide Stabilization: A Review. Indian J. Struct. Eng. 1 (2), 13-16. doi:10.35940/ijse.A1304.111221

Rauter, M., Hoße, L., Mulligan, R. P., Take, W. A., and Løvholt, F. (2021). Numerical Simulation of Impulse Wave Generation by Idealized Landslides with OpenFOAM. Coastal Eng. 165, 103815. doi:10.1016/j.coastaleng.2020.103815

Salmasi, F., Norouzi, R., Abraham, J., Nourani, B., and Samadi, S. (2020). Effect of Inclined clay Core on Embankment Dam Seepage and Stability through LEM and FEM. Geotech. Geol. Eng. 38 (6), 6571-6586. doi:10.1007/s10706-020-01455-7

Shaller, P. J., Doroudian, M., and Hart, M. W. (2020). The Eureka Valley Landslide: Evidence of a Dual Failure Mechanism for a Long-Runout Landslide. Lithosphere 2020 (1), 8860819. doi:10.2113/2020/8860819

Shan, W., Zhang, C., Guo, Y., Shan, M., Zeng, X., and Wang, C. (2020). “Climate Change and Surface Deformation Characteristics in Degradation Area of Permafrost in Lesser Khingan Mountain, China," in Understanding and Reducing Landslide Disaster Risk. WLF 2020. ICL Contribution to Landslide Disaster Risk Reduction. Editors V. Vilímek, F. Wang, A. Strom, K. Sassa, P. T. Bobrowsky, and K. Takara (Cham: Springer), 209-219. doi:10.1007/978-3030-60319-9_24

Stark, T. D., and Xu, Z. (2020). "Oso Landslide: Failure Mechanism and Runout Analyses," in Understanding and Reducing Landslide Disaster Risk. WLF 2020. ICL Contribution to Landslide Disaster Risk Reduction. Editors B. Tiwari, K. Sassa, P. T. Bobrowsky, and K. Takara (Cham: Springer), 47-63. doi:10.1007/978-3-030-60706-7_3

Wasowski, J., and Pisano, L. (2020). Long-term InSAR, Borehole Inclinometer, and Rainfall Records Provide Insight into the Mechanism and Activity Patterns of an Extremely Slow Urbanized Landslide. Landslides 17 (2), 445-457. doi:10.1007/s10346-019-01276-7

Xie, W.-1., Guo, Q., Wu, J. Y., Li, P., Yang, H., and Zhang, M. (2021). Analysis of Loess Landslide Mechanism and Numerical Simulation Stabilization on the Loess Plateau in Central China. Nat. Hazards 106 (1), 805-827. doi:10.1007/ s11069-020-04492-w

Yang, H., Wang, L. W., and Hao, S. W. (2020). Landslide Monitoring and its Stabilization Process Based on an In-Situ Tilt Monitoring System. Eng. Mech. 37 (S), 193-199. doi:10.6052/j.issn.1000-4750.2019.04.S035

Yang, W., Wang, F., Tie, Y., Wang, D., and Ouyang, C. (2021). Characteristics and Dynamic Process Modeling of the Rainfall-Induced Landslide on August 21, 2020 in Hanyuan County, China. Front. Earth Sci. 9, NA. doi:10.3389/ feart.2021.720872
Yin, X., Lin, H., Chen, Y., Tang, Y., Wang, Y., Zhao, Y., et al. (2021). Stability Analysis of Slope Considering the Energy Evolution of Locked Segment. Geotech. Geol. Eng. 1-10. doi:10.21203/rs.3.rs-191198/v1

Yu, B. T., Sun, H. Y., Shang, Y. Q., and Li, H. Q. (2006). Characteristics and Stability Analysis of Xiashan Landslide in Zhejiang Province. Chin. J. Rock Mech. Eng. 25, 2875-2881. doi:10.1007/s11631-006-0407-2

Zhang, J. M. (2020). State of Art and Trends of Rock Slope Stability with Soft Interlayer. J. Eng. Geol. 28 (3), 626-638. doi:10.13544/ j.cnki.jeg.2019-377

Zhang, Y. S., Renji, B., Sanshao, R., and Zongliang, L. (2020). An Analysis of GeoMechanism of the Baige Landslide in Jinsha River, Tibet. Geol. China 47 (6), 1637-1645. doi:10.12029/gc20200603

Zhao, S. Y., Zheng, Y. R., Shi, W. M., and Wang, J. L. (2002). Analysis on Safety Factor of Slope by Strength Reduction FEM. Chin. J. Geotech. Eng. 24 (3), 343-346. doi:10.3321/j.issn:1000-4548.2002.03.017

Zheng, H., Shi, Z., Shen, D., Peng, M., Hanley, K. J., Ma, C., et al. (2021). Recent Advances in Stability and Failure Mechanisms of Landslide Dams. Front. Earth Sci. 9, 201. doi:10.3389/feart.2021.659935

Zheng, S. Y., and Zhao, Y. R. (2005). Limit State Finite Element Method for Geotechnical Engineering Analysis and its Applications. Chin. Civ. Eng. J. 1. doi:10.3321/j.issn:1000-131X.2005.01.012

Zhou, J.-w., Li, H.-b., Lu, G.-d., Zhou, Y., Zhang, J.-y., and Fan, G. (2021). Initiation Mechanism and Quantitative Mass Movement Analysis of the 2019 Shuicheng Catastrophic Landslide. Q. J. Eng. Geology. Hydrogeology 54 (2), qjegh2020-052. doi:10.1144/qjegh2020-052

Zhu, C., He, M., Karakus, M., Cui, X., and Tao, Z. (2020). Investigating Toppling Failure Mechanism of Anti-dip Layered Slope Due to Excavation by Physical Modelling. Rock Mech. Rock Eng. 53 (11), 5029-5050. doi:10.1007/s00603-02002207-y

Zhu, J. W., Zhuang, H. Z., Li, J. W., Zhang, L. Q., and Yang, Z. F. (2008). RESEARCH ON REINFORCEMENT TECHNIQUE OF SLOP WITH LARGE DIMENSIONS. J. Eng. Geol. 16 (3), 365-370. doi:10.3969/j.issn.1004-9665.2008.03.014

Conflict of Interest: Author ZZ was employed by the company China Railway Construction Bridge Engineering Bureau Group 3rd Engineering Co.

The remaining authors declare that the research was conducted in the absence of any commercial or financial relationships that could be construed as a potential conflict of interest.

Publisher's Note: All claims expressed in this article are solely those of the authors and do not necessarily represent those of their affiliated organizations, or those of the publisher, the editors and the reviewers. Any product that may be evaluated in this article, or claim that may be made by its manufacturer, is not guaranteed or endorsed by the publisher.

Copyright (C) 2022 Bao, Zhan, Xia, Huang and Zhao. This is an open-access article distributed under the terms of the Creative Commons Attribution License (CC BY). The use, distribution or reproduction in other forums is permitted, provided the original author(s) and the copyright owner(s) are credited and that the original publication in this journal is cited, in accordance with accepted academic practice. No use, distribution or reproduction is permitted which does not comply with these terms. 